\section{INTERPOL (International Criminal Police Organization)}

Organization. INTERPOL was founded in 1923, disbanded in 1938 and reconstituted in 1946. The International Criminal Police Organization-INTERPOL was created to ensure and promote the widest possible mutual assistance between all criminal police authorities within the limits of the law existing in the different countries worldwide and the spirit of the Universal Declaration of Human Rights, and to establish and develop all institutions likely to contribute effectively to the prevention and suppression of ordinary law crimes.

Aims. INTERPOL provides a co-ordination centre (General Secretariat) for its 190 member countries. Its priority areas of activity concern criminal organizations, public safety and terrorism, drug-related crimes, financial crime and high-tech crime, trafficking in human beings and tracking fugitives from justice. INTERPOL centralizes records and information on international offenders; it operates a worldwide communication network.

INTERPOL's General Assembly is held annually. The General Assembly is the body of supreme authority in the organization. It is composed of delegates appointed by the members of the organization.

INTERPOL's Executive Committee, which meets four times a year, supervises the execution of the decisions of the General Assembly. The Executive Committee is composed of the president of the organization, the three vice-presidents and nine delegates.

INTERPOL's General Secretariat is the centre for co-ordinating the fight against international crime. Its activities, undertaken in response to requests from the police services and judicial authorities in its member countries, focus on crime prevention and law enforcement.

As of Feb. 2015 INTERPOL's Sub-Regional Bureaus were located in Abidjan, Bangkok, Buenos Aires, Harare, Nairobi, San Salvador and Yaoundé.

Headquarters: 200 Quai Charles de Gaulle, 69006 Lyon, France. Website: http://www.interpol.int

President: Mireille Ballestrazzi (France).

\section{Further Reading}

Martha, Rutsel Silvestre J., The Legal Foundations of INTERPOL. 2010 transportation, energy, natural resources, petro-chemical and other infrastructure-related sectors in member countries.

Members (56 as of Feb. 2015). Afghanistan, Albania, Algeria, Azerbaijan, Bahrain, Bangladesh, Benin, Brunei, Burkina Faso, Cameroon, Chad, Comoros, Côte d'Ivoire, Djibouti, Egypt, Gabon, Gambia, Guinea, Guinea-Bissau, Indonesia, Iran, Iraq, Jordan, Kazakhstan, Kuwait, Kyrgyzstan, Lebanon, Libya, Malaysia, Maldives, Mali, Mauritania, Morocco, Mozambique, Niger, Nigeria, Oman, Pakistan, Palestine, Qatar, Saudi Arabia, Senegal, Sierra Leone, Somalia, Sudan, Suriname, Syria, Tajikistan, Togo, Tunisia, Turkey, Turkmenistan, Uganda, United Arab Emirates, Uzbekistan, Yemen.

Official language: Arabic. Working languages: English, French. Headquarters: PO Box 5925, Jeddah 21432, Saudi Arabia.

Website: http://www.isdb.org

President: Ahmed Mohamed Ali Al-Madani (Saudi Arabia).

\section{Médecins Sans Frontières/Doctors Without Borders (MSF)}

Origin. Médecins Sans Frontières/Doctors Without Borders was founded in 1971 by a small group of doctors and journalists who believed that all people have a right to emergency relief.

Functions. MSF was one of the first non-governmental organizations to provide both urgently needed medical assistance and to publicly bear witness to the plight of the people it helps. Today MSF is an international medical humanitarian organization with 19 sections and several additional offices around the world. Every year MSF sends around 3,000 volunteer doctors, nurses, other medical professionals, logistical experts, water and sanitation engineers, and administrators to join approximately 25,000 locally hired staff to provide medical aid in over 60 countries. MSF was awarded the 1999 Nobel Peace Prize.

Headquarters: MSF International Office, Rue de Lausanne 78, CP 116, CH-1211 Geneva 21, Switzerland.

Website: http://www.msf.org

Secretary-General: Jérôme Oberreit (France).

International Council President: Dr Joanne Liu (Canada).

\section{Islamic Development Bank}

The Agreement establishing the IDB (Banque islamique de développement) was adopted at the Second Islamic Finance Ministers' Conference held in Jeddah, Saudi Arabia in Aug. 1974. The Bank, which is open to all member countries of the Organization of the Islamic Conference, commenced operations in 1975. Its main objective is to foster economic development and social progress of member countries and Muslim communities individually as well as jointly in accordance with the principles of the Sharia. It is active in the promotion of trade and the flow of investments among member countries, and maintains a Special Assistance Fund for member countries suffering natural calamities. The Fund is also used to finance health and educational projects aimed at improving the socio-economic conditions of Muslim communities in non-member countries. A US\$1.5bn. IDB Infrastructure Fund was launched in 1998 to invest in projects such as power, telecommunications,

\section{Nobel Prizes}

When the scientist, industrialist and inventor Alfred Nobel died in 1896, he made provision in his will for his fortune to be used for prizes in Physics, Chemistry, Physiology or Medicine, Literature and Peace. The Norwegian Nobel Committee awards the Nobel Peace Prize, and the Nobel Foundation in Stockholm (founded 1900; Mailing address: Box 5232, SE-10245, Stockholm, Sweden) awards the other four prizes plus the Sveriges Riksbank Prize in Economic Sciences in Memory of Alfred Nobel (often referred to as the Nobel Memorial Prize in Economic Sciences). The Prize Awarding Ceremony takes place on 10 Dec., the anniversary of Nobel's death. The last ten recipients of the Nobel Peace Prize, worth 8m. Sw. kr. in 2014 (the same as 2013 and 2012, which was down from $10 \mathrm{~m}$. Sw. kr. for the previous 11 years), are:

2005 - Mohamed ElBaradei and the IAEA for their efforts to prevent nuclear energy from being used for military purposes and 